\title{
A Simple Approach to Stepwise Synthesis of Graphene Oxide Nanomaterial
}

\section{Paulchamy $\mathrm{B}^{1}$, Arthi $\mathbf{G}^{2}$ and Lignesh BD $^{3}$}

${ }^{1}$ Professor and Head, Department of ECE, Hindusthan Institute of Technology, Coimbatore, India

${ }^{2} S R F$, International Advanced Research Centre for Power Metallurgy and New Materials, Hyderabad, India

${ }^{3}$ M. Tech (Nanotechnology) Student ,Anna University Regional Centre ,Coimbatore, India

\begin{abstract}
Technology research in nanotechnology promises breakthroughs in areas such as materials and manufacturing, nanoelectronics, medicine and healthcare, energy, biotechnology, information technology, and national security. One of the crucial bottlenecks for the application of graphene-based systems in materials science is their mass production. Meeting the requirements, graphene oxide (GO) has been considered widely as a prominent precursor and a starting material for the synthesis of this processable material. This work describes the synthesis of Graphene oxide (GO) by both Hummer's and Modified Hummer's method and its characterization by XRD, FT-IR spectroscopy and SEM. The results obtained from the characterization techniques mentioned above is also explained. This GO acts as a base material for the future application of water purification, super capacitors and as a composite in antibacterial activity, solar cells and coatings.
\end{abstract}

Keywords: Graphene oxide (GO); Hummer's method; Oxidation; XRD; FT-IR spectrum; SEM

\section{Introduction}

Nanoscience and nanotechnology primarily deal with the synthesis, characterization, exploration, and exploitation of nanomaterials. Carbon, one of the most common atoms on Earth, occurs naturally in many forms and as a component in countless substances which are called allotropes of carbon. Graphene, a "wonder material" is the world's thinnest, strongest, and stiffest material, as well as being an excellent conductor of heat and electricity. It is the basic building block of other important allotropes. Graphene oxide (GO) is of great interest due to its low cost, easy access, and widespread ability to convert to graphene. Scalability is also a much desired feature.

Graphene oxide is graphite that has been oxidized to intersperse the carbon layers with oxygen molecules, and then reduced, to separate the carbon layers completely into individual or few layer graphene. Graphene oxide is effectively a by-product of this oxidation as when the oxidizing agents react with graphite, the interplanar spacing between the layers of graphite is increased. The completely oxidized compound can then be dispersed in a base solution such as water, and graphene oxide is then produced [1-22].

A large number of oxygen-containing functional groups have been introduced onto both sides of a single graphite sheet (namely, graphene). The implantation of functional groups overcomes the intersheet van der Waals force and enlarges the interlayer spacing. The sheets in such an expanded structure are then easily pulled open using an external force such as sonication. That is, the expanded graphite is exfoliated into multi-layered or even single-layered sheets. Generally, the oxidized graphene sheets, namely, GO, acquire multiple defects and the degree of the defects is subject to the additive amount of oxidant and the oxidizing time [22]. GO is produced by the oxidative treatment of graphite by one of the principle methods developed by Brodie, Hummers or Staudenmeir.

\section{Properties of GO}

Graphene oxide, like graphite oxide, is often described as an electrical insulator, due to the disruption of its $\mathrm{sp}^{2}$ bonding networks. In actuality, this is not entirely true. The ability for graphene oxide to conduct electrons depends on the amount of oxidization in the compound, as well as the method of synthesis. It's the oxidization in the solution that disturbs electrical conductivity, so while highly oxidized graphene oxide would be a very poor conductor of electricity, even if graphene oxide were to be heavily reduced, though it would possibly be able to conduct electricity, it would still not perform as well as high quality graphene monolayers in terms of electron mobility.

However, there are methods that can be used to counteract this situation, and those are by a process often referred to as functionalization, which means to chemically modify a substance in order to develop its properties to suit a specific application. The main properties include: 1) Hygroscopicity, 2) Dispersibility and 3) Toxicity [23-31].

Functionalization of graphene oxide can fundamentally change graphene oxide's electrical properties. The resulting chemically modified graphenes (CMGs) could then potentially become much more adaptable for almost limitless applications. There are many ways in which graphene oxide can be functionalized, depending on the desired application.

\section{Methods and Materials}

GO consists of graphene sheets decorated mostly with epoxide and hydroxyl groups. Rapid heating of GO results in expansion and delamination, due to evaporation of the intercalated water and evolution of gases from pyrolysis of the oxygen containing functional groups. The structure and properties of GO depend on the synthesis

*Corresponding author: Paulchamy Balaiah, Professor and Head, Department of ECE, Hindusthan Institute of Technology, Coimbatore, India, Tel: 0422-4393113; E-mail: balurjp@yahoo.co.in

Received November 07, 2014; Accepted December 16, 2014; Published January 01,2015

Citation: Paulchamy B, Arthi G, Lignesh BD (2015) A Simple Approach to Stepwise Synthesis of Graphene Oxide Nanomaterial. J Nanomed Nanotechnol 6: 253. doi: 10.4172/2157-7439.1000253

Copyright: (C 2015 Paulchamy B, et al. This is an open-access article distributed under the terms of the Creative Commons Attribution License, which permits unrestricted use, distribution, and reproduction in any medium, provided the original author and source are credited. 
method and degree of oxidation. The most common method of synthesis is chemical method of synthesis by Hummer's method [28]. This method of synthesis can be varied by varying the oxidizing agents used to exfoliate graphite flakes. Here, we represent two method of synthesis technique one is by common method and other by modified method of synthesis namely, Hummer's and Modified Hummer's method of synthesis.

\section{Chemicals required}

Graphite Flakes (acid treated 99\%, Asbury Carbons), Sodium nitrate (98\%, Nice chemicals), Potassium permanganate (99\%, RFCL), Hydrogen peroxide (40\% wt, Emplura), Sulphuric acid (98\%, ACS), Hydrochloric acid (35\%, RANKEM).

\section{Hummer's method of synthesis}

Graphene oxide was synthesized by Hummers method through oxidation of graphite. The stepwise preparation is given as follows:

1. Graphite flakes $(2 \mathrm{~g})$ and $\mathrm{NaNO}_{3}(2 \mathrm{~g})$ were mixed in $50 \mathrm{~mL}$ of $\mathrm{H}_{2} \mathrm{SO}_{4}(98 \%)$ in a $1000 \mathrm{~mL}$ volumetric flask kept under at ice bath $\left(0-5^{\circ} \mathrm{C}\right)$ with continuous stirring.

2. The mixture was stirred for $2 \mathrm{hrs}$ at this temperature and potassium permanganate $(6 \mathrm{~g})$ was added to the suspension very slowly. The rate of addition was carefully controlled to keep the reaction temperature lower than $15^{\circ} \mathrm{C}$.

3. The ice bath was then removed, and the mixture was stirred at $35^{\circ} \mathrm{C}$ until it became pasty brownish and kept under stirring for 2 days.

4. It is then diluted with slow addition of $100 \mathrm{ml}$ water. The reaction temperature was rapidly increased to $98^{\circ} \mathrm{C}$ with effervescence, and the color changed to brown color.

5. Further this solution was diluted by adding additional $200 \mathrm{ml}$ of water stirred continuously.

6. The solution is finally treated with $10 \mathrm{ml} \mathrm{H}_{2} \mathrm{O}_{2}$ to terminate the reaction by appearance of yellow color.

7. For purification, the mixture was washed by rinsing and centrifugation with $10 \% \mathrm{HCl}$ and then deionized (DI) water several times.

8. After filtration and drying under vacuum at room temperature, the graphene oxide (GO) was obtained as a powder.

\section{Modified Hummer's method of synthesis}

This modified method of synthesis involves both oxidation and exfoliation of graphite sheets due to thermal treatment of solution. The stepwise synthesis method is given as follows:

1. Graphite flakes $(2 \mathrm{~g})$ and $\mathrm{NaNO}_{3}(2 \mathrm{~g})$ were mixed in $90 \mathrm{~mL}$ of $\mathrm{H}_{2} \mathrm{SO}_{4}(98 \%)$ in a $1000 \mathrm{ml}$ volumetric flask kept under at ice bath $\left(0-5^{\circ} \mathrm{C}\right)$ with continuous stirring.

2. The mixture was stirred for $4 \mathrm{hrs}$ at this temperature and potassium permanganate $(12 \mathrm{~g})$ was added to the suspension very slowly. The rate of addition was carefully controlled to keep the reaction temperature lower than $15^{\circ} \mathrm{C}$.

3. The mixture is diluted with very slow addition of $184 \mathrm{ml}$ water and kept under stirring for $2 \mathrm{hrs}$. The ice bath was then removed, and the mixture was stirred at $35^{\circ} \mathrm{C}$ for $2 \mathrm{hrs}$.
4. The above mixture is kept in a reflux system at $98^{\circ} \mathrm{C}$ for $10-15$ min. After $10 \mathrm{~min}$, change the temperature to $30^{\circ} \mathrm{C}$ which gives brown colored solution.

5. Again after $10 \mathrm{~min}$, change it to $25^{\circ} \mathrm{C}$, and maintain the temperature for $2 \mathrm{hrs}$

6. The solution is finally treated with $40 \mathrm{ml} \mathrm{H}_{2} \mathrm{O}_{2}$ by which color changes to bright yellow.

7. $200 \mathrm{ml}$ of water is taken in two separate beakers and equal amount of solution prepared is added and stirred for $1 \mathrm{hr}$.

8. It is then kept without stirring for 3-4 hrs, where the particles settles at the bottom and remaining water is poured to filter.

9. The resulting mixture is washed repeatedly by centrifugation with $10 \% \mathrm{HCl}$ and then with deionized (DI) water several times until it forms gel like substance (pH- neutral).

10. After centrifugation the gel like substance is vacuum dried at $60^{\circ} \mathrm{C}$ for more than $6 \mathrm{hrs}$ to $\mathrm{GO}$ powder.

The following Figure 1 shows the synthesized GO solution as well as powder form.

\section{Results and Discussions}

The synthesized GO by Hummer's and Modified Hummer's methods are characterized by X-Ray Diffraction Analysis (XRD), Fourier Transform- Infrared Spectroscopy (FT-IR), Raman Spectroscopy, Scanning Electron Microscopy (SEM) \& FESEM.

\section{XRD analysis}

The X-ray diffraction (XRD) is the most widely used technique for general crystalline material characterization. It is used to Measure the average spacing's between layers or rows of atoms, determine the orientation of a single crystal or grain. The XRD pattern obtained for as synthesized GO nanoparticles by Hummer's method is shown in Figure 2.

It shows the diffraction peak at $2 \theta=10^{\circ}$, which is mainly due to the oxidation of graphite. The diffraction peak of pure graphite is found around $26^{\circ}$, corresponding to the highly organized layer structure with an interlayer distance of $0.34 \mathrm{~nm}$ along the (002) orientation is shown as inset in Figure 2. The XRD pattern for synthesized GO by Modified Hummer's method is shown in Figure 3.

The disappearance of the peak at $26^{\circ}$ and appearance of the peak at $10^{\circ}$, shows that the product is completely oxidized after the chemical oxidation and exfoliation, indicating an increase in d-spacing from $0.34 \mathrm{~nm}$ to $0.82 \mathrm{~nm}$.

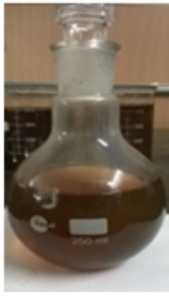

GO Solution

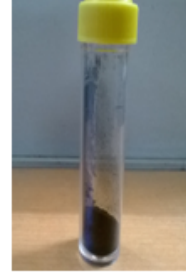

GO Powder
Figure 1: Images of synthesized GO solution and powder. 
Citation: Paulchamy B, Arthi G, Lignesh BD (2015) A Simple Approach to Stepwise Synthesis of Graphene Oxide Nanomaterial. J Nanomed Nanotechnol 6: 253. doi: 10.4172/2157-7439.1000253

Page 3 of 4

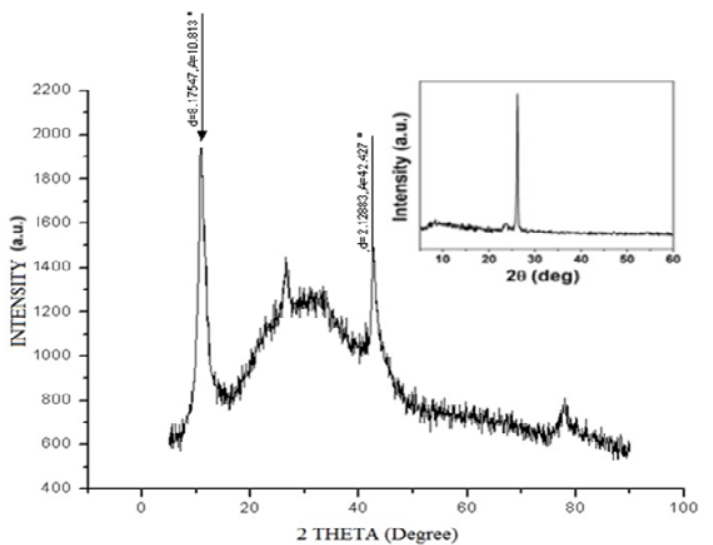

Figure 2: XRD of GO by Hummer's method (inset shows XRD of graphite).

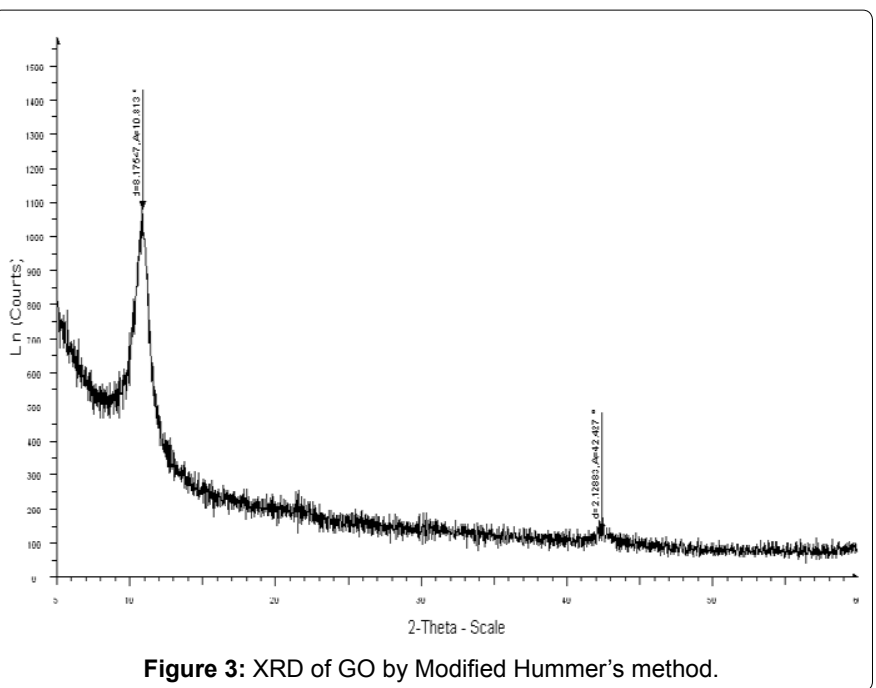

\section{FT-IR analysis}

It is a technique adopted to obtain an infrared spectrum of absorption, emission, and photoconductivity of a solid, liquid or gas. Also it can be utilized to quantitative analysis of an unknown mixture. FTIR measurement was employed to investigate the bonding interactions in graphene before and after the oxidation process. It assumes the intensities of the peaks are directly related to the amount of sample present.

Figure 4 shows that synthesized GO has a peak at $1081 \mathrm{~cm}^{-1}$ which is attributed to the $\mathrm{C}-\mathrm{O}$ bond, confirming the presence of oxide functional groups after the oxidation process. The peaks in the range of $1630 \mathrm{~cm}^{-1}$ to $1650 \mathrm{~cm}^{-1}$ show that the $\mathrm{C}=\mathrm{C}$ bond still remained before and after the oxidation process. The absorbed water in GO is shown by a broad peak at $2885 \mathrm{~cm}^{-1}$ to $3715 \mathrm{~cm}^{-1}$, contributed by the $\mathrm{O}-\mathrm{H}$ stretch of $\mathrm{H}_{2} \mathrm{O}$ molecules. This supports the fact that $\mathrm{GO}$ is a highly absorptive material, as verified by its ability to become a gel-like solution.

\section{SEM analysis}

Scanning Electron microscopy provides morphology and structure of nanomaterials. Figure 5a shows the SEM image of typical graphite. From SEM image it is clear that how the sheets are stalked together in Figure $5 \mathrm{a}$. Figure $5 \mathrm{~b}$ shows the SEM image of exfoliated GO. It clearly shows that how the graphene sheets are exfoliated.

\section{FESEM analysis}

The grain size and surface morphology were observed by the field emission scanning electron microscope (FESEM). FESEM images of the Graphene Oxide (GO) have well defined and interlinked three-dimensional Graphene sheets, forming a porous network that resembles a loose sponge like structure as shown in Figure 6.

\section{Raman spectrum analysis}

Raman spectroscopy is a widely used tool for the characterization of carbon products, especially considering the fact that conjugated \& double carbon- carbon bonds lead to high Raman intensities. Figure 7

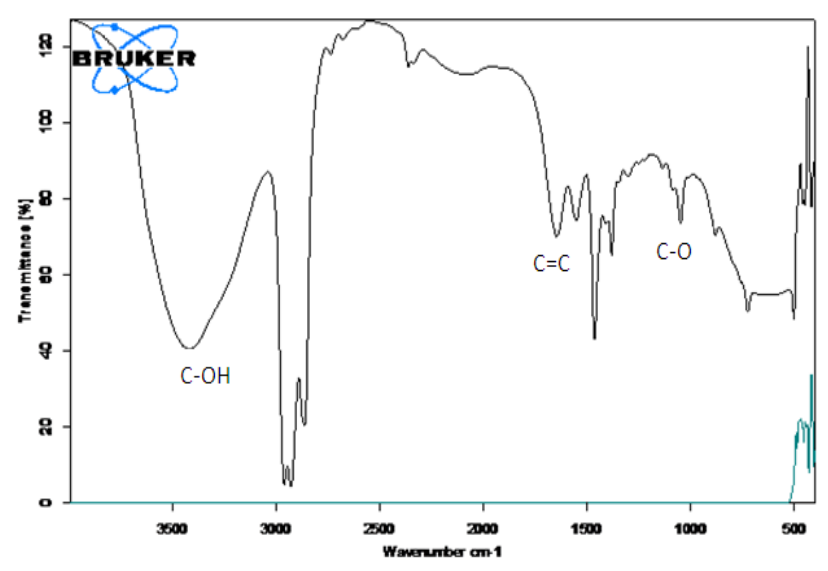

Figure 4: FT-IR spectrum of GO.

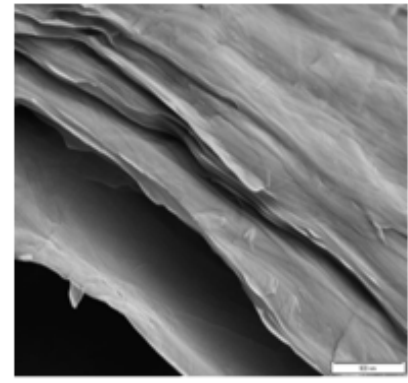

(a)

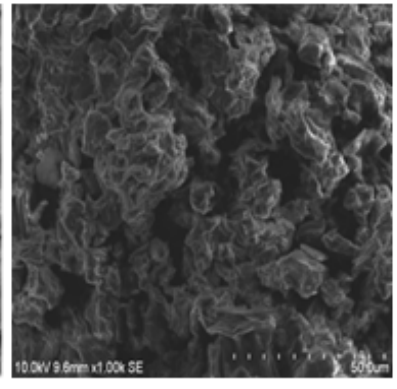

(b)
Figure 5: SEM images of (a) Graphite and (b) GO.

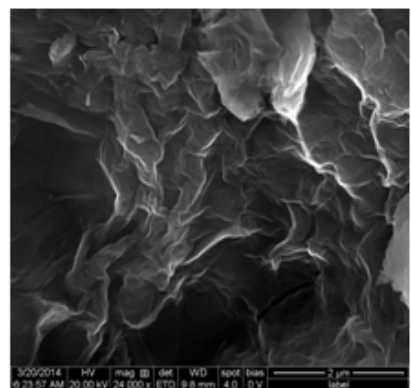

(a)

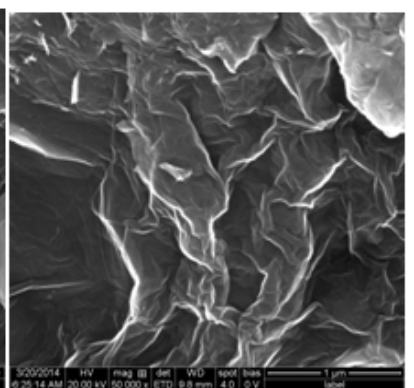

(b)
Figure 6: FESEM images of GO at magnification (a) 24000 and (b) 50000. 
Citation: Paulchamy B, Arthi G, Lignesh BD (2015) A Simple Approach to Stepwise Synthesis of Graphene Oxide Nanomaterial. J Nanomed Nanotechnol 6: 253. doi: 10.4172/2157-7439.1000253

Page 4 of 4

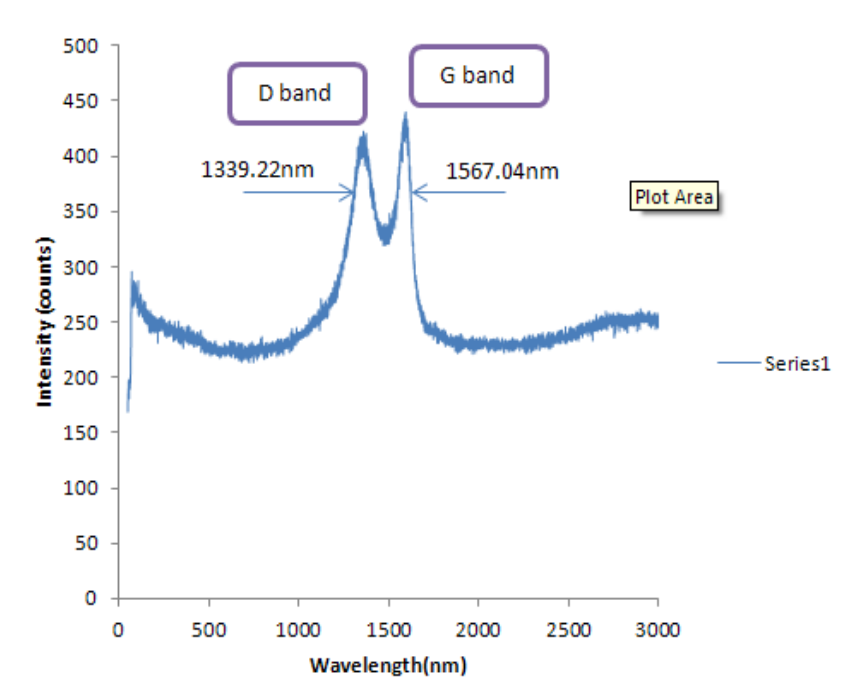

Figure 7: Raman Spectrum of GO.

shows the Raman spectrum of GO, where the in-phase vibration (G band) of GO is at $1567.04 \mathrm{~nm}$ and the disorder band ( $\mathrm{D}$ band) of GO is at $1339.22 \mathrm{~nm}$.

\section{Conclusion}

The Graphene oxide thus synthesized by Hummer's \& Modified Hummer's method in this work shows the simple and convenient method of synthesis. This work confirms the existence of oxygen functional groups by $\mathrm{XRD}$ and presence of $\mathrm{C}-\mathrm{O}$ and $\mathrm{C}=\mathrm{C}$ bonds by FT-IR analysis. Also the exfoliation of graphene sheets is confirmed by SEM image. Thus, the synthesized GO shows many interesting and unique properties that can be applied in variety of applications.

\section{References}

1. Balaprasad, Farah (2012) Water soluble graphene synthesis. Chemical Science Transactions 10: 500-507.

2. Ban FY, Majid SR, Huang NM, Lim HN (2012) Graphene Oxide and Its Electrochemical Performance. Int J Electrochem Sci 7: 4345-4351.

3. Benjamin (2011) Growing graphene via chemical vapour deposition.

4. http://www.nanowerk.com/nanotechnology/introduction/introduction_to_ nanotechnology_1.php

5. Cecilia M, Goki E, Stefano A, Steve M, Andre K, et al. (2009) Evolution of Electrical, Chemical, and Structural Properties of Transparent and Conducting Chemically Derived Graphene Thin Films. Adv Funct Mater 19: 2577-2583.

6. Chenliang S, Kian PL (2011) Carbocatalysts: Graphene oxide and its derivatives. Acc Chem Res 46: 2275-2285.

7. Daniel R, Sungjin P, Christopher W, Rodney S (2010) The chemistry of graphene oxide. Chem Soc Rev 39: 228-240.

8. Daniela C, Dmitry V, Jacob M, Alexander S, Zhengzong S, et al. (2010) Improved Synthesis of Graphene Oxide. ACS Nano 4: 4806-4814.

9. Deep J, Anchal S, Pulickel A (2011) Graphene synthesis and band gap opening.

10. http://arxiv.org/ftp/arxiv/papers/1212/1212.6413.pdf

11. Geim AK, Novoselov KS (2007) The rise of grapheme. Nature materials 6: 183 191.

12. Goki E, Manish C (2010) Chemically Derived Graphene Oxide: Towards LargeArea Thin-Film Electronics and Optoelectronics. Adv Material 22: 2392-2415.

13. Gunasekaran V, Karthikeyan K, Rajneesh M, Sang K (2012) An investigation of the electrical transport properties of graphene-oxide thin films. Materials Chemistry and Physics 132: 29-33.

14. Grzegorz S, Jaroslaw S, Joanna J, Rafal K, Mariusz Z, et al. (2012) Graphene Oxide Vs Reduced Graphene Oxide as saturable absorbers for Er-doped passively mode-locked fiber laser. Optics Express 20: 19463-19473.

15. Heyrovska R (2008) Atomic structures of graphene, benzene and methane with bond lengths as sums of the single, double and resonance bond radii of carbon.

16. Hofmann U, Holst R (1939) Über die Säurenatur und die Methylierung von Graphitoxyd. Chem Ges 72: 754-771.

17. Huang NM, Lim HN, Chia CH, Yarmo MA, Muhamad MR (2011) Simple roomtemperature preparation of high-yield large-area graphene oxide. International Journal of Nanomedicine 6: 3443-3448.

18. Hui X, Qing Y, Fan L, Linsheng T, Xingchun Z, et al. (2013) A graphene-based platform for fluorescent detection of SNPs. Analyst 138: 2678-2682.

19. Kian P, Qiaoliang B, Manish C (2010) Graphene oxide as a chemically tunable platform for optical applications. Nature Chemistry 2: 1015-1024.

20. Laura JC, Jaemyung K, Vincent CT, Jiayan L, Franklin K, et al. (2011) Graphene oxide as surfactant sheets. Pure Appl Chem 83: 95-110.

21. Lewis G, Zhang Y, Chongwu Z (2011) Large Scale Graphene by Chemical Vapor Deposition: Synthesis, Characterization and Applications.

22. Ling S, Bunshi F (2000) Massive production of graphene oxide from expanded graphite.

23. Long Z, Jiajie L, Huang Y, Yanfeng M, Yongsheng C (2009) Size-controlled synthesis of graphene oxide sheets on a large scale using chemical exfoliation. Carbon 47: 3365-3368.

24. Ramendra SD, Ranjan K, Retna C, Panigrahi MK (2012) Rapid room temperature chemical route for the synthesis of graphene: Metal-mediated reduction of graphene oxide. Chemical Communications.

25. Sasha, Dmitriy A, Richard D, Kevin A, SonBinh T, et al. (2007) Synthesis of graphene-based nanosheets via chemical reduction of exfoliated graphite oxide. Carbon 8: 1558-1565.

26. Sohan C (2012) Bulk synthesis of Graphene Nanosheets.

27. Viet HP, Phamm HD, Thanh TD, Sunwook K, Jin SC, et al. (2012) Chemical reduction of an aqueous suspension of graphene oxide by nascent hydrogen. Journal of Materials Chemistry 22: 10530-10536

28. Vimlesh C, Kwang S (2011) Highly Selective Adsorption of $\mathrm{Hg}^{2+}$ by PolypyrroleReduced Graphene Oxide Composite. Chemical Communications 47: 3942 3944.

29. Virendra S, Daeha J, Zhai L, Das S, Sudipta IK, et al. (2011) Graphene based materials: Past, present and future. Progress in Materials Science 56: 11781271.

30. Vorrada L, Krit T, Passakorn E, Wanchai B, Achanai B (2013) Preparation and Characterization of Reduced Graphene Oxide Sheets via Water-Based Exfoliation and Reduction Methods. Advances in Materials Science and Engineering 2013: 923403.

31. Wei (2012) Graphite Oxide: Structure, Reduction and Applications. 